\title{
Multiscale evaluation of a thin-bed reservoir
}

\author{
Anita Lis-Śledziona \\ Oil and Gas Institute - National Research Institute, Krakow, Poland; e-mail: lis@inig.pl; ORCID ID: 0000-0003-3067-3014 \\ (C) 2021 Author. This is an open access publication, which can be used, distributed and reproduced in any medium according \\ to the Creative Commons CC-BY 4.0 License requiring that the original work has been properly cited.
}

Received: 1 March 2021; accepted: 1 April 2021; first published online: 27 April 2021

\begin{abstract}
A thin-bed laminated shaly-sand reservoir of the Miocene formation was evaluated using two methods: high resolution microresistivity data from the XRMI tool and conventional well logs. Based on high resolution data, the Earth model of the reservoir was defined in a way that allowed the analyzed interval to be subdivided into thin layers of sandstones, mudstones, and claystones. Theoretical logs of gamma ray, bulk density, horizontal and vertical resistivity were calculated based on the forward modeling method to describe the petrophysical properties of individual beds and calculate the clay volume, porosity, and water saturation. The relationships amongst the contents of minerals were established based on the XRD data from the neighboring wells; hence, the high-resolution lithological model was evaluated. Predicted curves and estimated volumes of minerals were used as an input in multimineral solver and based on the assumed petrophysical model the input data were recalculated, reconstructed and compared with the predicted curves. The volumes of minerals and input curves were adjusted during several runs to minimalize the error between predicted and recalculated variables. Another approach was based on electrofacies modeling using unsupervised self-organizing maps. As an input, conventional well logs were used. Then, the evaluated facies model was used during forward modeling of the effective porosity, horizontal resistivity and water saturation. The obtained results were compared and, finally, the effective thickness of the reservoir was established based on the results from the two methods.
\end{abstract}

Keywords: thin bed, high resolution well logs prediction, horizontal resistivity, unsupervised neural network, self-organizing maps (SOM), electrofacies, low resistivity pay

\section{INTRODUCTION}

The purpose of this study was to evaluate a laminated reservoir consisting of thin beds of sandstones, mudstones, and claystones. In a thin-bed reservoir, the conductivity of clay laminations is often much higher than in gas or oil sand laminations. Unfortunately, due to the vertical resolution of logging tools, the recorded resistivity is low. Low resistivity intervals with higher clay volume could be omitted during the interpretation as they will not indicate the presence of gas or oil. Each logging tool has its own definition of a thin layer. Essentially, each layer that is thinner than the vertical resolution of the logging tool might be consider a thin bed. There are several data processing techniques that can be used to enhance the vertical resolution of conventional logs and sharpen low-resolution ones. These methods are described in depth by Allen (1984), Chapman et al. (1987), Boyd et al. (1995), Ramamoorthy et al. (1995). All of the described methods require at least one high-resolution curve and the methods are based on the correlation between high resolution and conventional logs. The situation is much more complicated if there is no or very weak correlation between high resolution and conventional logs. This is due to the presence of very thin layers. The high resolution microresitivity data was recorded with a sampling rate of $0.0025 \mathrm{~m}$ (394 samples per meter) and can resolve laminas of $0.5 \mathrm{~cm}$ of thickness while the vertical resolution of conventional logs ranges from 46 to $61 \mathrm{~cm}$. 
This paper presents alternative approaches to evaluating thin bedded gas horizons.

The technique used to increase the resolution depends on the available software, as well as the available well $\log$ data. Table 1 shows the available well logs in well M-1 and their vertical resolution.

Table 1

Vertical resolution of well logs from well M-1

\begin{tabular}{|l|c|}
\hline \multicolumn{1}{|c|}{ Well log } & Vertical resolution [cm] \\
\hline NPHS & 61 \\
\hline RHOB & 46 \\
\hline PE & 48 \\
\hline DT & 61 \\
\hline HRAI (Rt, Rx0) & 30.5 \\
\hline XRMI & 0.5 \\
\hline
\end{tabular}

Archival wells usually have limited data sets, mainly consisting of basic well logs like: gamma ray, neutron porosity, spontaneous potential and several resistivity logs with a different investigation depth. Fortunately, some of the old wells have high resolution microresistivity data available. This paper presents two attempts to evaluate thin bed reservoir, the first with the use of high resolution microresistivity data and the second dedicated to wells with limited data sets with no high-resolution logs available. The second approach was based on electrofacies determination using unsupervised Kohonen self-organizing maps (Kohonen 2001).

\section{Geological settings and input data}

The Carpathian Foredeep (Fig. 1A) is known from multi-horizon gas-bearing sandstone and mudstone located in Miocene sediments. The Miocene reservoirs are saturated by high methane content (95-99\%) gas (Myśliwiec 2004). The evaluated reservoir consists of thin, silty, and sandy horizontal layers (Krzywiec et al. 2008).

In the evaluated well, the well log data including gamma rays, neutron porosity, bulk density, and compressional slowness, were recorded with a sampling rate equal to $0.0762 \mathrm{~m}$. The analyzed reservoir consisted of laminas that were a few centimeters thick $(2-5 \mathrm{~cm})$; these zones are too thin to be resolved by a common logging tool. Instead, the tools read average resistivity of several layers. The formation resistivity in the reservoir zone did not exceed $4 \Omega \cdot \mathrm{m}$. This kind of horizon was discovered mainly due to perforations that produced gas flow. The reservoir zone in well M-1 has a thickness of $104.5 \mathrm{~m}$, and perforation covers almost the whole reservoir interval, resulting in a gas flow of $105 \mathrm{~m}^{3} / \mathrm{min}$.

A detailed study of high resolution microresistivity logs allowed the evaluation of beds and their thicknesses. The underlying series of sandstone and mudstone were also found to dip at small angles (1 degree) in the same direction (W). The mineral composition of the Miocene heteroliths mainly included quartz (20-47\%), carbonaceous (5-22\%), K-Feldspar (5-10\%), and Plagioclase (up to 10\%). The clay minerals present were illit (10-17\%), illit/smectite (6-15\%), montmorillonite (7-15\%), chlorite (4-9\%), and kaolinite (1-3\%). The presence of K-Feldspar caused an increase of the gamma ray log values in the sandstone intervals. The presence of mudstones containing iron compounds were also observed (Jarzyna et al. 2009). These mudstones can be noticed on well log data as they cause significant resistivity drops.

\section{METHODS}

\section{High resolution model evaluation based on microresistivity well log}

This section describes reservoir evaluation using high resistivity logging measurements. The well $\log$ data was recorded in water-based mud. The presence of thin layers of clay caused the resistivity values to decrease in these intervals. The resistivity logs from the High-Resolution Array Induction (HRAI) measuring horizontal resistivity are more sensitive to detect resistivity changes in individual beds, their vertical resolution is equal to $30.5 \mathrm{~cm}$ $(1 \mathrm{ft})$. However, it is still below the beds thickness, the layers are too thin to be spotted by this tool, the variable did not show any significant increase in resistivity in the gas-saturated intervals. Dipmeter data or high-resolution images of borehole wells provide useful information about the dips, and enable the identification of the thicknesses of thin beds (Serra \& Andreani 1991, Ruhovets 1992, Shahinpour 2013, Nooh et al. 2017). The analyzed well drilled through several gas-bearing horizons, some of them formed as clean sandstones. 


\section{A THE CARPATHIAN FOREDEEP}

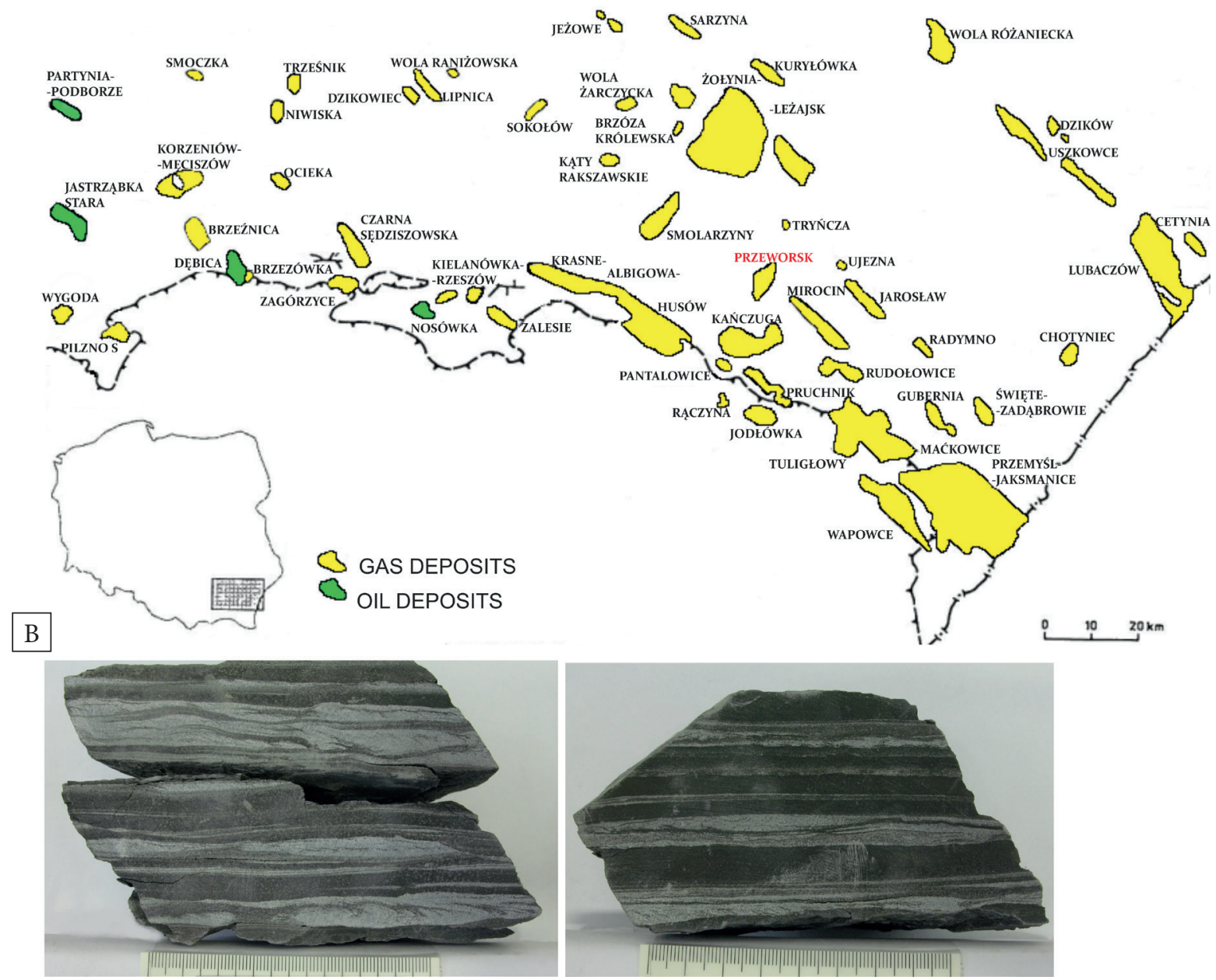

Fig. 1. Map of the distribution of natural gas and oil reservoirs in the Carpathian Foredeep (modified from Borys 1996), the gas field marked in red is the subject of interpretation (A). Miocene heteroliths, thin lamination of claystones and sandstones (B)

The properties of the clean sandstone intervals were assumed to be similar to the properties of thin sand laminas, and the thin layers of claystones were similar to thick layers of claystones that seal sandstone reservoirs. Claystone has low resistivity as it holds water inside, as bound water helps an electrical current to pass through the rock easily. The analyzed interval was characterized by almost no water production; thus, the log-derived water saturation values were considered to represent irreducible water saturation. The high-resolution resistivity image shows dark, low-resistivity laminated clay and high-resistivity, gas-saturated sandstone. The highest resistivity indicates the presence of sandstone, moderate resistivity indicates silt/mudstone, and low resistivity indicates clay. Depth matching of the high-resolution log and conventional logs was performed. Estimation of the high-resolution clay volume ( $\mathrm{Vcl}$ ) was carried out in two attempts. First, the clay volume was estimated using a high-resolution resistivity (RES_HR) curve based on the resistivity Equation (1):

$$
\mathrm{Vcl}=\frac{\log 10\left(\mathrm{RES}_{-} \mathrm{HR}\right)-\log 10\left(\mathrm{R}_{\text {sand }}\right)}{\log 10\left(\mathrm{R}_{\mathrm{cl}}\right)-\log 10\left(\mathrm{R}_{\text {sand }}\right)}
$$

where:

RES_HR - the high-resolution resistivity read from the log at each depth,

$\mathrm{R}_{\mathrm{cl}}$ - the resistivity of claystone (high resolution),

$\mathrm{R}_{\text {sand }}$ - the resistivity of sandstone (high resolution). 
The second method to calculate the clay volume was performed with the Stieber-Miocene Pliocene equation (Serra 1984) using predicted estimated high-resolution GR log (GR_HR). High resolution XRMI data (RES_HR) were used as a clay indicator (Vcli) and normalized to API units according to Equation (2):

$$
\mathrm{GR}_{-} \mathrm{HR}=\left(\mathrm{Vcli}_{-}-\mathrm{Vcli}_{\text {min }}\right) \cdot \frac{\mathrm{API}_{\text {max }}-\mathrm{API}_{\text {min }}}{\mathrm{Vcli}_{\text {max }}-\mathrm{Vcli}_{\text {min }}}+\mathrm{API}_{\text {min }}
$$

where:

Vcli - the clay indicator $(\mathrm{Vcli}=$ =1/RES_HR),

$\mathrm{Vcli}_{\text {max }}, \mathrm{Vcli}_{\text {min }}$ - the maximum and minimum values of $\mathrm{Vcl}$,

$\mathrm{API}_{\max }, \mathrm{API}_{\min }$ - the assumed values of the gamma rays in API units for individual lithological benchmarks (claystone and sandstone):

$\mathrm{API}_{\max }=\mathrm{GRcl}, \mathrm{API}_{\min }=\mathrm{GRsand}$,

GR_HR - the values of high-resolution gamma ray in API units.

The minimum and maximum limits for sharp gamma rays were taken from a thick, conventional clean sandstone interval and thick layers of claystone. The results from the two methods were compared, and the final clay volume was calculated. The porosity was evaluated using the multi-well correlation performed on laboratory data between the clay volume and effective porosity. Based on the relationship between the bulk density and laboratory measured (Mercury Injection Porosimetry) effective porosity from neighboring wells, it was also possible to calculate a high-resolution bulk density curve (RHOB_HR). When laboratory data were available, this method seemed to be more accurate for predicting proper bulk density values than the forward modeling method. The results show that clay laminas have a much higher bulk density than porous sandstone, and this can be up to $2.6 \mathrm{~g} / \mathrm{cm}^{3}$ (Fig. 2B).

These predicted high-resolution logs are tool responses that reflect petrophysical changes due to the different properties of each thin bed. The well log processing enabled the calculation of the enhanced GR_HR and RHOB_HR logs and to evaluate the high-resolution clay volume (Vcl_HR) and effective porosity (PHIE_HR).
The available XRD analysis from neighboring wells allowed the estimation of the volumes of carbonaceous, feldspar, and quartz; thus, the sharp high resolution lithological model was created. The quartz volume showed a strong dependence with the clay volume (Fig 2C).

The calculation of the most important parameter, water saturation, also required the use of high-resolution resistivity data. Commonly, deep resistivity logs are used to estimate water saturation. Unfortunately, the recorded deep resistivity in thin bed reservoirs does not reflect the real resistivity of individual beds. Additionally, the non-linear response of the resistivity to the volume of clays and their distribution in the formation meant that the recorded resistivity was averaged. The thickness of thin beds which is below the vertical resolution of the logging tool, together with the high conductivity of clay, means that conventional measured resistivity cannot be used in water saturation estimation since it would lead to the underestimation of the hydrocarbon volume. This issue was resolved with the use of the anisotropic laminar model described by Klein (1993), Mollison et al. (2001), and Bała (2011) to derive true formation resistivity (3). In terms of the geometric mean, Rv_HR is the electric resistivity measured vertically to the bedding and Rh_HR is the electric resistivity measured horizontally to the bedding:

$\frac{1}{\mathrm{Rh}_{-} \mathrm{HR}}=\frac{\mathrm{Vcl}_{-} \mathrm{HR}}{\mathrm{R}_{\mathrm{cl}}}+\frac{\text { Vsand_HR }}{\mathrm{R}_{\text {sand }}}$

$\mathrm{Rv} \_\mathrm{HR}=\mathrm{Vcl} \_\mathrm{HR} \cdot \mathrm{R}_{\mathrm{cl}}+\mathrm{Vsand} \_\mathrm{HR} \cdot \mathrm{R}_{\mathrm{sand}}$

where:

Vcl_HR - the high-resolution volume of laminated clay in a fraction,

Vsand_HR - the high-resolution sand volume in a fraction $=(1-$ Vcl_HR $)$,

$\mathrm{R}_{\mathrm{cl}}$ - the resistivity of laminated clay,

$\mathrm{R}_{\text {sand }}$ - the resistivity of sand.

$\mathrm{Rh} \_$HR in the vertical well where beds are horizontals is equal to Rt_HR.

Formation resistivity Rt will be equivalent to the clay and sand resistances; therefore:

$\frac{1}{\mathrm{Rh} \_\mathrm{HR}}=\frac{1}{\mathrm{Rt} \_\mathrm{HR}}$ 
Thus:

$\frac{1}{\mathrm{R}_{\text {sand }}}=\left(\frac{1}{\mathrm{Rh}_{-} \mathrm{HR}}-\frac{\mathrm{Vcl}_{-} \mathrm{HR}}{\mathrm{R}_{\mathrm{cl}}}\right) \cdot\left(\frac{1}{\mathrm{Vsand}_{-} \mathrm{HR}}\right)$

The resistivity of clay $\left(\mathrm{R}_{\mathrm{c}}\right)$ can be determined from adjacent thick clay. In addition, if the gas saturated interval is analyzed and perforations show almost no water production, and there is also another gas-saturated clean sandstone horizon present in the well, the resistivity of sand can be taken from this adjacent gas-saturated interval, and Rh_HR can be calculated using Equation (3). Then, for thin beds of sandstones, high resolution water saturation (SW_HR) can be calculated using Archie's equation:

$$
\mathrm{SW} \_\mathrm{HR}=\left(\frac{a \cdot \mathrm{R}_{\mathrm{w}}}{\mathrm{PHIE}_{-} \mathrm{HR}^{m} \cdot \mathrm{Rh}_{-} \mathrm{HR}}\right)^{\frac{1}{n}}
$$

where:

$$
a \text { - tortuosity }
$$

$\mathrm{R}_{\mathrm{w}}$ - the formation's water resistivity,

PHIE_HR - the high-resolution effective porosity,

$m$ - the cementation exponent,

$n$ - the saturation exponent.
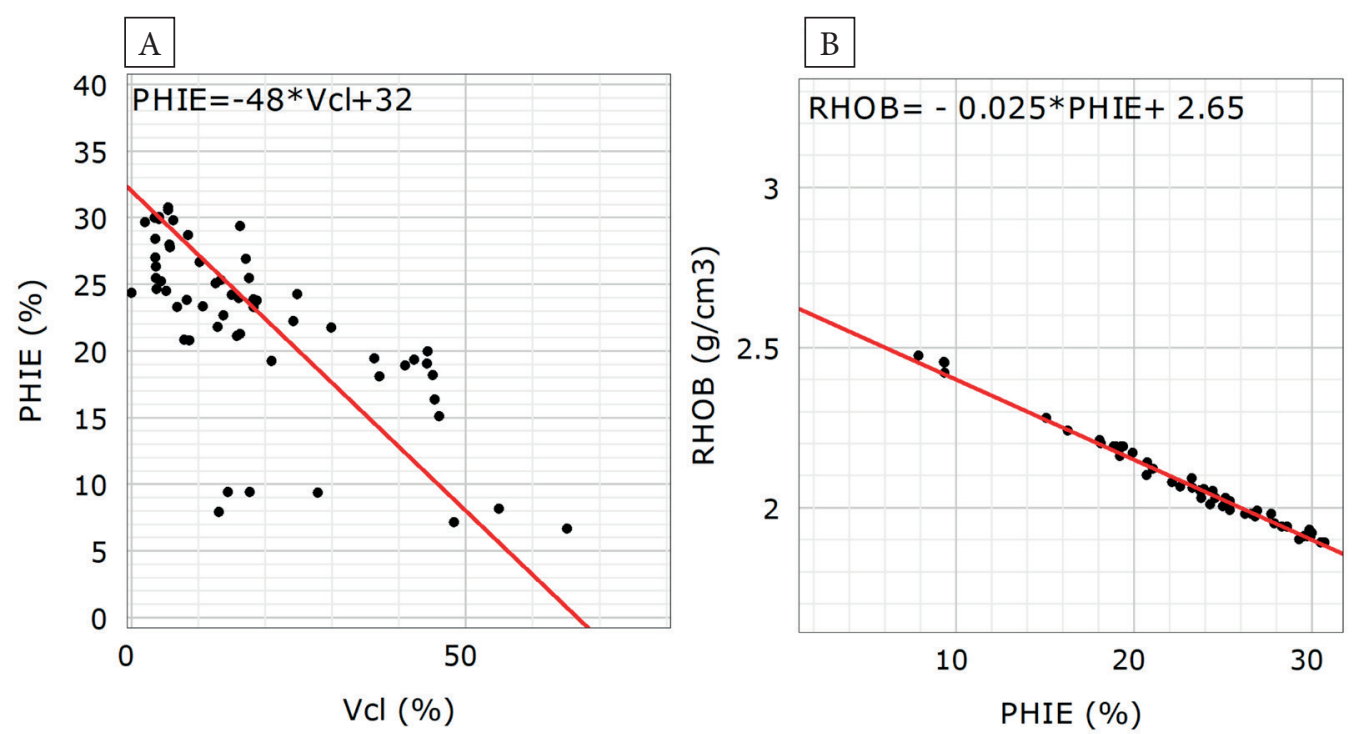

C
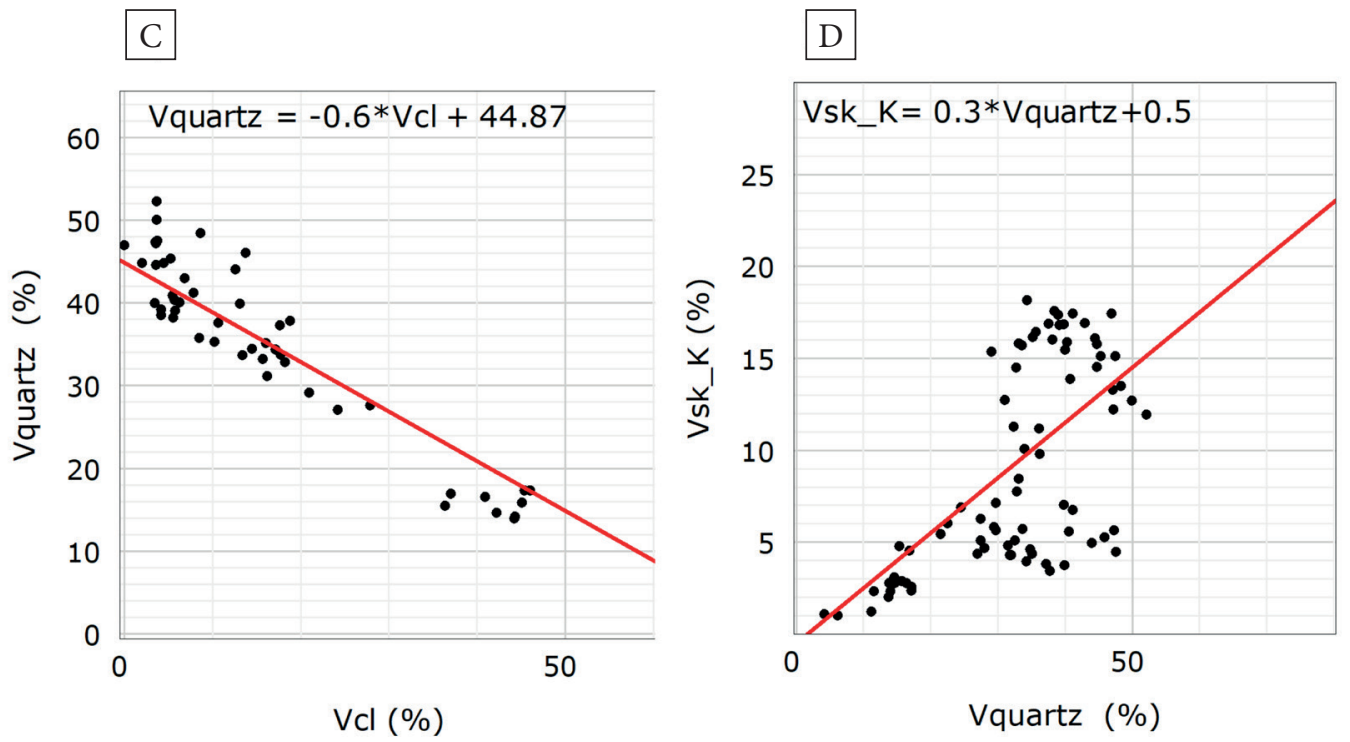

Fig. 2. Multi-well cross-plot of the measured effective porosity (PHIE) and total clay volume (Vcl) (A); multi-well cross-plot of the measured effective porosity (PHIE) and bulk density (RHOB) (B); correlation between clay volume and quartz (Vquartz) content based on XRD data (C); correlation between quartz volume and K-Feldspar volume (Vsk_K) based on XRD data (D) 
The current that flows vertically through the formation (Rv_HR) will always fall into a value between horizontal resistivity (Rh_HR) and sand resistivity $\left(\mathrm{R}_{\text {sand }}\right)$. The horizontal resistivity Rh_HR was calculated according to Equation (3), assuming $\mathrm{R}_{\mathrm{cl}}=2$ and $\mathrm{R}_{\text {sand }}=20$. NMR laboratory data from neighboring wells were also used. Measured free fluid saturation, defined as Kp3/PHIE, was correlated with the effective porosity (PHIE). As there was no water production in the zone of interest, the level of free fluid should be close to hydrocarbon saturation (Sh) and (1-Sh) capillary water saturation based on NMR laboratory measurements (SWI_NMR). The predicted, high-resolution gamma ray, bulk density and horizontal resistivity can also be validated using one of the predictive methods.

In this paper, the Quanti Elan module of Schlumberger software was used to validate the predicted high-resolution variables. Additionally, based on XRD laboratory data, estimated curves of mineral contents were used as "constant tool" with assigned uncertainty.

The assumed petrophysical model has the form of:

Vcl (wet clay-with bound water) + Vsk_K + + Vcalcite + Vquartz + PHIE.

Effective porosity is the porosity of a matrix without clay bound water (CBW). Besides CBW, there is also capillary water that occupies the very small pores of the matrix:

$\mathrm{PHIT}=\mathrm{PHIE}+\mathrm{CBW}=$ $=\mathrm{Kp} 1+\mathrm{Kp} 2+\mathrm{Kp} 3, \mathrm{CBW}=\mathrm{Kp} 1$.

The results of Nuclear Magnetic Resonance can be interpreted as:

$\mathrm{Kp1}$ - clay bound water (CBW),

Kp2 - capillary bound water - water held in very small pores of the matrix,

Kp3 - free fluids.

Then:

PHIE $=$ Kp2 + Kp3.

In conventional reservoirs, only pore spaces occupied by free fluids can be hydrocarbon saturated. Kp2 is related to very small pores of the matrix and in this paper is called capillary water saturation (SWI). The amount of capillary water depends on the clay volume and effective porosity and can be determined from Zawisza's equation (Zawisza \& Nowak 2012):

$\mathrm{SWI}=\mathrm{Vcl}^{a} \cdot(1-\mathrm{PHIE})^{b}$,

where $a$ and $b$ are core calibration constants.

Zawisza \& Nowak (2012) estabilished the values of $\mathrm{a}$ and $\mathrm{b}$ for different oil and gas deposits in Poland.

Table 2

Bulkdensityand gamma rayvalues assigned to each component

\begin{tabular}{|l|c|c|}
\hline \multicolumn{1}{|c|}{ Component } & RHOB_RH & GR_HR \\
\hline Clay & 2.79 & 150 \\
\hline Quartz & 2.65 & 30 \\
\hline K-Feldspar & 2.57 & 170 \\
\hline Calcite & 2.71 & 11 \\
\hline
\end{tabular}

In the component specification table (Tab. 2) petrophysical properties were assigned to each component. The use of a multimineral solver was an iterative process where, based on the predictive modeled curves and properties assigned to the model components, we tried to evaluate the lithology so that it would be consistent with the results of the XRD data, laboratory measured porosity and water saturation. On the other hand, we aimed to minimize the error between the estimated input curves and those recalculated in $\mathrm{QE}$ module based on the evaluated lithological model. To do so, we can either adjust the volumes of minerals, change the assigned properties of minerals or recalculate the input curves. After several runs, the modification of input curves, estimated clay volume and the adjustment of predicted mineral volumes, the final petrophysical model was determined. Table 3 shows the root mean square error (RMSE), correlation coefficient (R) and coefficient of determination $\left(R^{2}\right)$ between predicted and recalculated variables in the $\mathrm{QE}$ module. 
Table 3

Comparison between predicted and calculated (QE module) variables

\begin{tabular}{|l|c|c|c|c|c|}
\hline \multicolumn{1}{|c|}{ Parameter } & $\begin{array}{c}\text { Predicted } \\
\text { variable }\end{array}$ & $\begin{array}{c}\text { Variables calculated } \\
\text { in QE module }\end{array}$ & RMSE & R & $\mathbf{R}^{2}$ \\
\hline Gamma ray & GR_HR & GR_QE & 1.24 & 0.994 & 0.989 \\
\hline Bulk density & RHOB_HR & RHOB_QE & 0.024 & 0.954 & 0.911 \\
\hline XRMI micro resistivity & RES_HR & RES_QE & 0.011 & 0.979 & 0.958 \\
\hline Formation resistivity & Rh & Rh_QE & 0.062 & 0.795 & 0.632 \\
\hline Effective porosity & PHIE_HR & PHIE_QE & 0.019 & 0.914 & 0.835 \\
\hline Clay volume & Vcl_HR & Vcl_QE & 0.009 & 0.996 & 0.992 \\
\hline K-Feldspar volume & Vsk_K_HR & K-Feldspar_QE & 0.008 & 0.957 & 0.916 \\
\hline Quartz volume & Vps__HR & Quartz_QE & 0.009 & 0.99 & 0.98 \\
\hline Carbonaceous volume & Vwap_HR & Calcite_QE & 0.008 & 0.896 & 0.802 \\
\hline Water saturation & SW_HR & SW_QE & 0.066 & 0.917 & 0.84 \\
\hline
\end{tabular}

\section{Petrophysical model evaluation based on electrofacies (SOM)}

Electrofacies identification was performed using unsupervised classification, with no assumption about the facies classification being made and with no indexation input. The grouping method was Ward clustering. Seven well logs were used as inputs: gamma ray (GR), neutron porosity (NPHS), compressional slowness (DT), bulk density (RHOB), photoelectric factor (PE), formation and flushed zone resistivity (Rt, $\mathrm{Rx} 0$ ) measured with the High-Resolution Array Induction (HRAI). The size of the topological map was set to $7 \times 7$. The goal of the SOM analysis was lithology classification to predict when sandstone, mudstone or claystone is present at specific depth. The weight for each input was equal to 1 . The net was trained in the M-1 well without using the high-resolution log. This experiment was made to check how the neural network with deals in thin bed analysis if no high-resolution data is available and if it helps to enhance the interpretation. It was observed that due to the presence of thin beds, the petrophysical parameters did not change significantly throughout the reservoir. They were an average of the thin laminas of sandstones and claystone. The use of SOM helped to detect detailed changes and subdivide this heterogenous reservoir into four different electrofacies. Table 4 shows the variance and average values of input data in each of the identified units.

Table 4

The variance and average input data values in each of the identified units

\begin{tabular}{|c|c|c|c|c|c|c|c|c|}
\hline \multirow[t]{2}{*}{ Variable } & \multicolumn{2}{|c|}{ Claystone $\left(\mathrm{F}_{\mathrm{cl}}\right)$} & \multicolumn{2}{|c|}{ Mudstone $\left(\mathrm{F}_{\text {mud }}\right)$} & \multicolumn{2}{|c|}{$\begin{array}{c}\text { Fine-grained } \\
\text { sandstone }\left(\mathrm{F}_{\text {sand }}\right)\end{array}$} & \multicolumn{2}{|c|}{$\begin{array}{l}\text { Mudstones with iron } \\
\text { compound }\left(\mathrm{F}_{\mathrm{ir}}\right)\end{array}$} \\
\hline & mean & variance & mean & variance & mean & variance & mean & variance \\
\hline Gamma ray & 89.1497 & 6.5725 & 83.0164 & 5.6096 & 83.4363 & 1.0505 & 87.1696 & 2.2617 \\
\hline Neutron porosity & 0.3606 & 0.0000 & 0.3585 & 0.0001 & 0.3405 & 0.0000 & 0.3644 & 0.0000 \\
\hline Compressional slowness & 397.0245 & 8.0816 & 396.5339 & 2.6974 & 397.3999 & 18.8854 & 394.6939 & 4.6172 \\
\hline Bulk density & 2.3680 & 0.0001 & 2.3751 & 0.0000 & 2.3492 & 0.0002 & 2.3780 & 0.0000 \\
\hline Formation resistivity & 3.1283 & 0.0051 & 3.0860 & 0.0342 & 3.2009 & 0.0009 & 1.8179 & 0.0816 \\
\hline Photoelectric factor & 3.1958 & 0.0014 & 3.2447 & 0.0028 & 3.1030 & 0.0016 & 3.1860 & 0.0006 \\
\hline Flushed zone resistivity & 2.9994 & 0.0036 & 2.9421 & 0.0349 & 3.0697 & 0.0003 & 1.7793 & 0.0665 \\
\hline
\end{tabular}



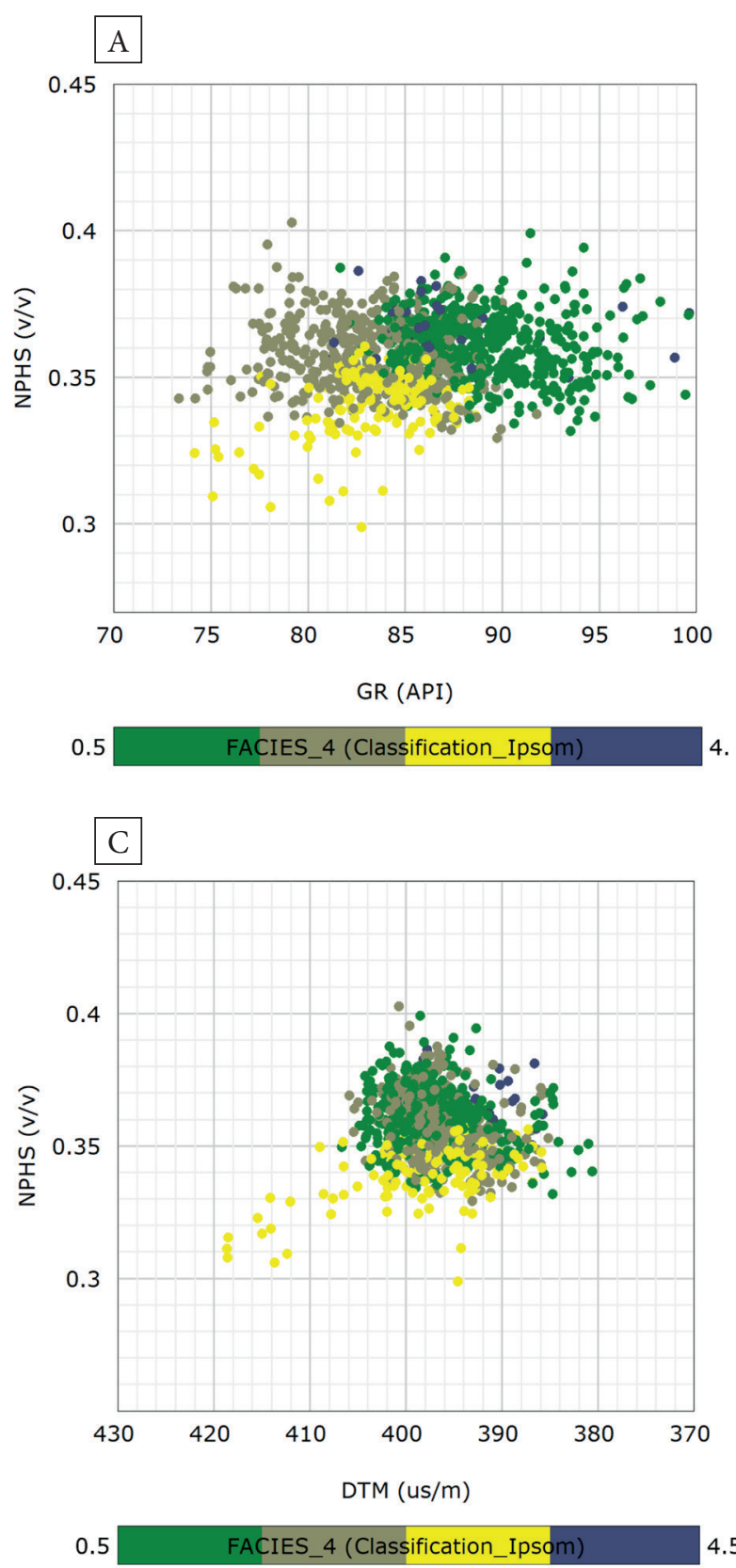

claystones

mudstones
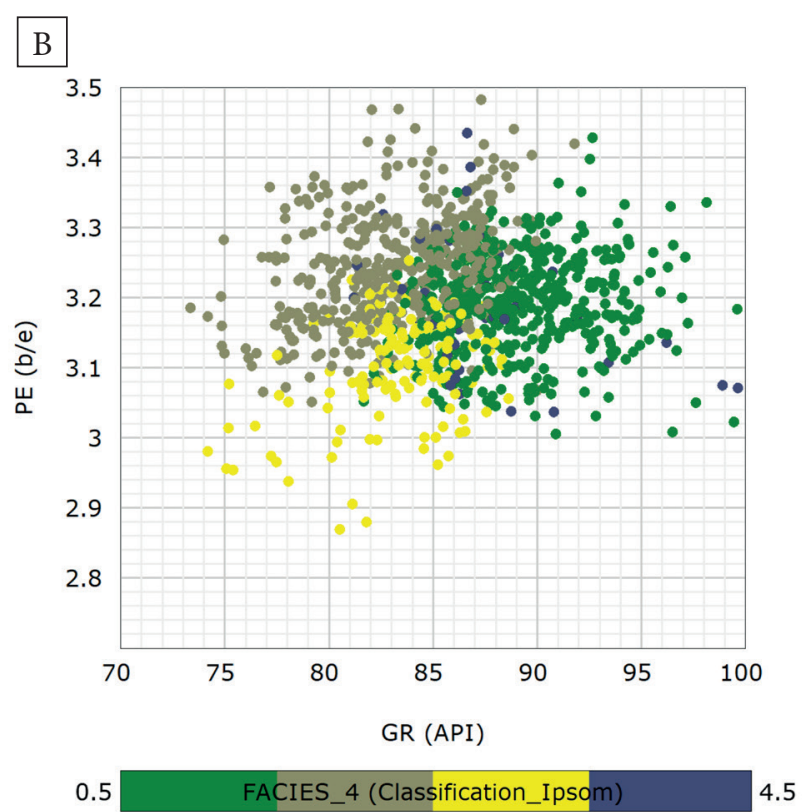

$\mathrm{D}$

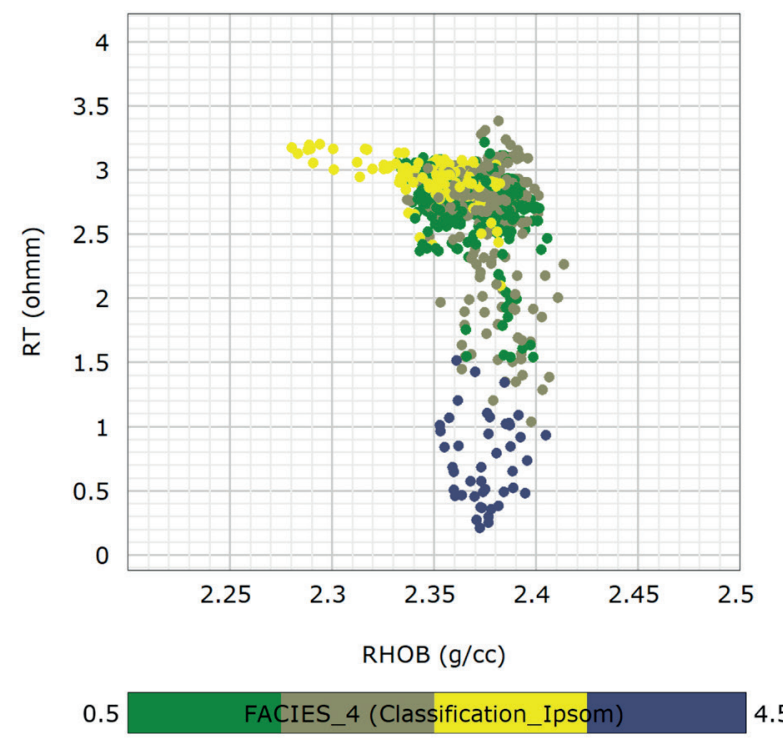

fine-grained sandstones

mudstones with iron compunds

Fig. 3. Cross-plots: gamma ray and neutron porosity (A); gamma ray and photoelectric factor (B); neutron porosity and compressional slowness (C); formation resistivity and bulk density (D)

Figure 3 is a graphical presentation of facies properties. The sandstone facies $\left(\mathrm{F}_{\text {sand }}\right)$ with the highest porosity are characterized by the lowest neutron porosity and bulk density and the highest formation resistivity related to gas filled pores of the reservoir rock. The slightly higher gamma ray values in comparison to mudstone facies might be related to the presence of 
K-Feldspar in the sandstone intervals. The mudstone facies $\left(\mathrm{F}_{\mathrm{mud}}\right)$ has a lower porosity and lower resistivity. The claystone facies $\left(\mathrm{F}_{\mathrm{cl}}\right)$ definitely has the highest gamma ray values, with an average value equal to 89 API. The high neutron porosity is related to the presence of clay-bound water. The slightly higher resistivity with comparison to mudstone facies is due to the different resistivity of clay-bound water. The mudstone with the iron compound $\left(\mathrm{F}_{\mathrm{ir}}\right)$ is characterized by the lowest resistivity values with an average of $1.8 \Omega \cdot \mathrm{m}$ (Fig. 3D) and also a low compressional slowness value. Nevertheless, the changes in petrophysical parameters between the identified electrofacies were found to be minor. These changes were captured by the neural network and classified as different petrophysical units. The properties of the identified units are presented in Figure 3. The proper performance of the classification was the first and most important step. The next stage was to estimate the effective porosity and formation resistivity according to the facies properties. Besides the electrofacies classification curve, the final output of the SOM were also curves associated with a probability of occurrence for the predicted facies at each depth.

This probability curve, together with the effective porosity assigned to each facies based on core analyses from the neighbored wells, enabled the proper enhanced effective porosity to be calculated (PHIE_F) using Equation (8):

PHIE_F $=\mathrm{pf}_{\mathrm{cl}} \cdot$ PHIE $_{\mathrm{cl}}+\mathrm{pf}_{\mathrm{mud}} \cdot$ PHIE $_{\mathrm{mud}}+$

$+\mathrm{pf}_{\text {sand }} \cdot \mathrm{PHIE}_{\text {sand }}+\mathrm{pf}_{\mathrm{ir}} \cdot \mathrm{PHIE}_{\mathrm{ir}}$

where:

$$
\begin{aligned}
& \mathrm{pf}_{\mathrm{cl}}, \mathrm{pf}_{\text {mud }} \text {, } \\
& \mathrm{pf}_{\text {sand }}, \mathrm{pf}_{\mathrm{ir}} \text { - the probability curves of the occur- } \\
& \text { rence of predicted facies at each } \\
& \text { depth: } \\
& \mathrm{pf}_{\mathrm{cl}}+\mathrm{pf}_{\text {mud }}+\mathrm{pf}_{\text {sand }}+\mathrm{pf}_{\mathrm{ir}}=1 \text {, } \\
& \mathrm{PHIE}_{\mathrm{cl}} \text { - the effective porosity of claystone } \\
& \text { (0.02), } \\
& \text { PHIE }_{\text {mud }} \text { - the effective porosity of mudstone } \\
& \text { (0.08), } \\
& \mathrm{PHIE}_{\text {sand }} \text { - the effective porosity of fine-grained } \\
& \text { sandstone (0.22), } \\
& \mathrm{PHIE}_{\mathrm{ir}} \text { - the effective porosity of mudstone } \\
& \text { with iron compounds (0.01). }
\end{aligned}
$$

The horizontal resistivity was calculated similarly to the porosity. After modification of Equation (3), Equation (9) was established:

$$
\frac{1}{\mathrm{Rh}}=\frac{\mathrm{pf}_{\mathrm{cl}}}{\mathrm{R}_{\mathrm{cl}}}+\frac{\mathrm{pf}_{\text {mud }}}{\mathrm{R}_{\text {mud }}}+\frac{\mathrm{pf}_{\text {sand }}}{\mathrm{R}_{\text {sand }}}+\frac{\mathrm{pf}_{\text {ir }}}{\mathrm{R}_{\mathrm{ir}}}
$$

where:

$\mathrm{pf}_{\mathrm{cl}}, \mathrm{pf}_{\text {mud }}$,

$\mathrm{pf}_{\text {sand }}, \mathrm{pf}_{\mathrm{ir}}$ - the probability curves of the occurrence of predicted facies at each depth: $\mathrm{pf}_{\mathrm{cl}}+\mathrm{pf}_{\text {mud }}+\mathrm{pf}_{\text {sand }}+\mathrm{pf}_{\mathrm{ir}}=1$,

$\mathrm{R}_{\mathrm{cl}}$ - the resistivity of claystones $(2 \Omega)$,

$\mathrm{R}_{\text {mud }}$ - the resistivity of mudstones $(8 \Omega)$,

$\mathrm{R}_{\text {sand }}$ - the resistivity of sandstone $(15 \Omega)$,

$\mathrm{R}_{\mathrm{ir}}$ - the resistivity of mudstone with iron compounds $(1 \Omega)$.

The final step of the interpretation was the calculation of the water saturation coefficient (SW) according to Equation (10). The values of effective porosity (PHIE_F) and horizontal resistivity (Rh) were used as inputs. The saturation coefficient $(n)$ was set to 1.8 , and the cementation coefficient $(m)$ was equal to 1.8:

$$
\mathrm{Rh}=\frac{\mathrm{R}_{\mathrm{w}}}{\mathrm{SW}^{n} \cdot \mathrm{PHIE}_{-} \mathrm{F}^{m}}
$$

\section{Model comparison}

Figure 4 presents the histograms of effective porosity (PHIE_F) and water saturation (SW_F) values based on IPSOM electrofacies modeling. The histogram shows the bimodal distribution of effective porosity with the highest values of $15-25 \%$ for sandstones and mudstones. Water saturation coefficient in clean sandstones is equal to $20-25 \%$ while in mudstones this increases to $60-65 \%$. The intervals with water saturation higher than $70 \%$ are not perspective. The high-resolution results with a sampling rate of $0.0025 \mathrm{~m}$ were filtered with a Gaussian filter to match the sampling rate of $0.1 \mathrm{~m}$ and the correlation between effective porosities obtained from two methods was performed, the correlation coefficient was low, $\mathrm{R}=0.275$, and the reason for this is that the input data for the porosity calculation were collected by two different tools with different levels of sensitivity and resolution. It was observed that the correlation was better in the intervals built with thicker layers of clay 
and sandstone and weaker when the laminas were very thin. Unfortunately, the conventional logging tool is not able to resolve such thin laminas; nevertheless, it provides a better solution than conventional interpretation methods. It enabled us to enhance the porosity values according to the electrofacies properties. A better correlation was observed between PHIE_F and the conventionally calculated porosity values based on the neutron-density cross-plot (PHIE_FIN). The correlation coefficient was equal to $R=0.42$. Apart from the fact that the use of SOM and conventional well logs will not provide a better resolution of the reservoir, it has advantages in thin bed evaluation:

- It enables the detection of zones with different petrophysical properties. It does not detect every layer, but it helps identify intervals of the best and poor accumulation properties.

- Based on the subdivided units we can model the properties of each unit (porosity, horizontal resistivity) by assigning different petrophysical properties to each electrofacies.
- The conventional interpretation does not provide appropriate input for reservoir interpretation. It averages the values from several thin layers. Based on electrofacies and core analysis, we can recalculate the real properties of each facies and calculate water saturation based on enhanced effective porosity and horizontal resistivity.

Figure 5 shows the histograms of high-resolution effective porosity and water saturation. The color scale refers to high resolution resistivity values. The highest porosity of $20-30 \%$ corresponds to the sandstone intervals. Higher variability can be observed in the water saturation coefficient in sandstone layers of $20 \%$ to even $60 \%$, while the gas saturated sandstones in Figure 4 have water saturation values of between $20-40 \%$. High resolution low resistivity claystone layers are fully water saturated similarly to the mudstones with iron compounds. In mudstones, depending on shaileness and effective porosity, the water saturation coefficient varies from $60-100 \%$
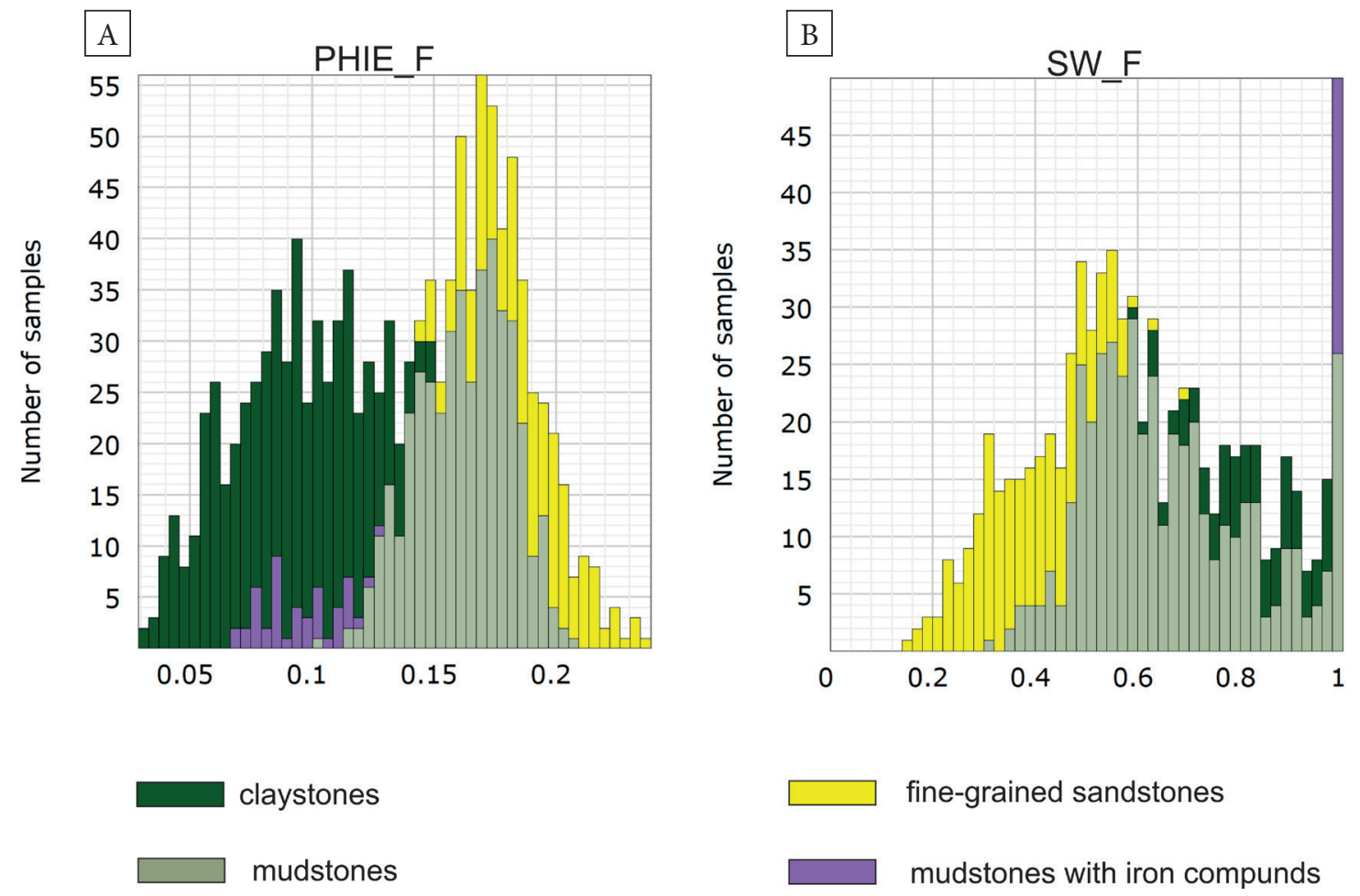

Fig. 4. Histograms of effective porosity (PHIE_F) (A) and water saturation (SW_F) (B); the color scale refers to electrofacies classification 


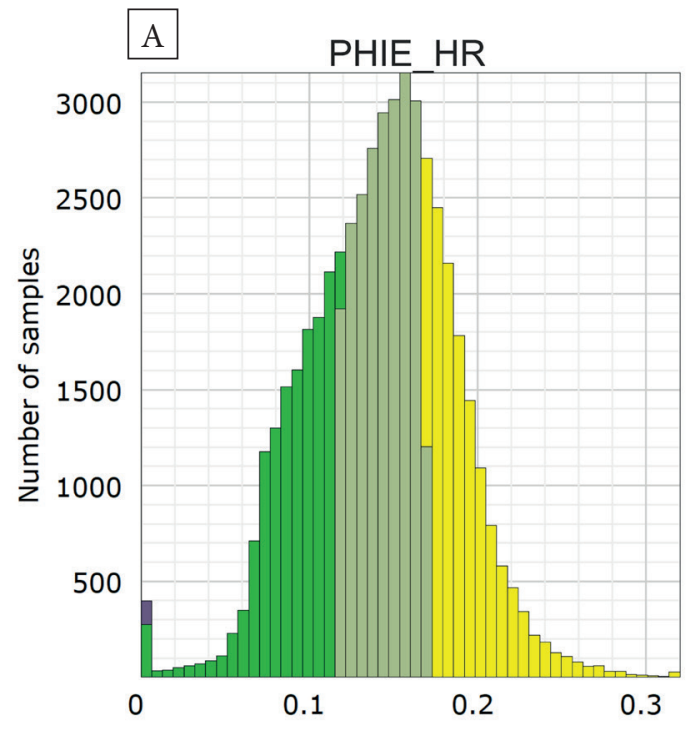

claystones

mudstones

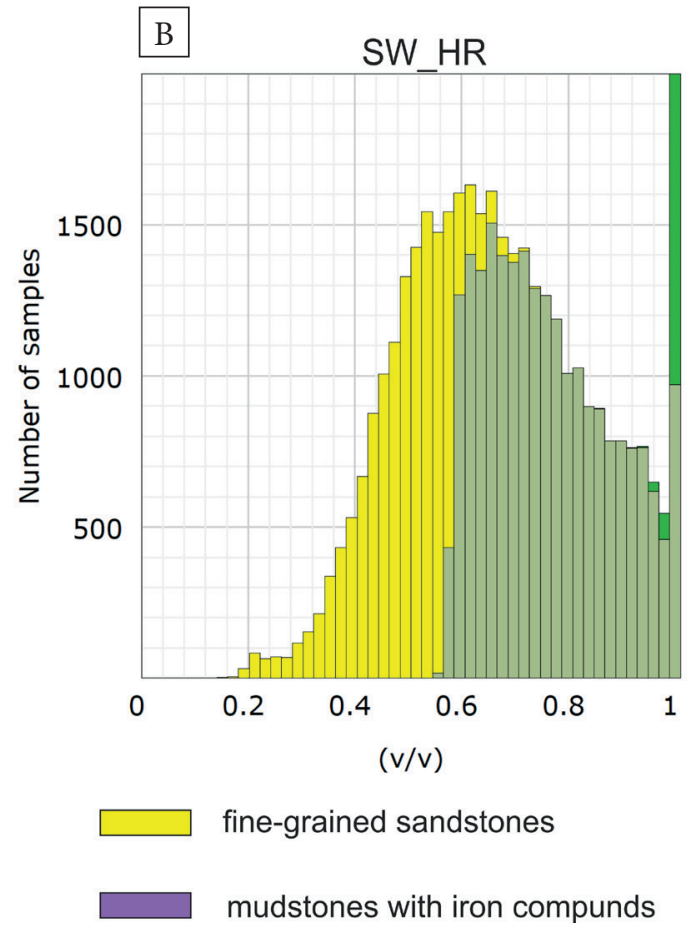

Fig. 5. Histograms of high resolution effective porosity (A) and high-resolution water saturation (B); the color scale refers to the high-resolution resistivity values, sandstone intervals correspond to high resistivity intervals, mudstones medium resistivity while the lowest values to claystones and mudstones with iron compounds

\section{RESULTS}

Figure 6 presents the high resolution (sampling rate $0.0025 \mathrm{~m}$ ) results of interpretation based on the microresistivity data in comparison with the conventional interpretation of a four meters interval of the reservoir presented in the second track. This is followed by high-resolution resistivity logs measured and calculated in the Quanti Elan module on the third track. Similarly measured gamma ray GR, predicted GR_HR and GR_QE recalculated in multimineral solver are in the fourth column. The fifth track shows bulk density values: measured (RHOB), predicted RHOB_HR and recalculated RHOB_QE. Column six contains predicted and calculated formation resistivity values ( $\mathrm{Rh}$ and Rh_QE) also measured formation resistivity (Rt) is shown. Track seven is a comparison of predicted and evaluated water saturation values. Column eight shows the difference between calculated effective porosities. Then, columns from nine to twelve present volumes of minerals, calculated based on the correlation with the laboratory data and evaluated in QE module. Track 13 shows a microresistivity map with lamination of dark, low-resistivity clay interbedded with high-resistivity sandstones. It can be observed that the dark intervals of clay seen on the resistivity map correspond to thin layers of nonporous claystone. The difference between predicted and forward modeled in QE module curve is marked in orange at each track. The last track presents the evaluated high resolution lithological model.

Figure 7 is the final presentation of the results obtained from both the high-resolution method and the electrofacies based modeling approach. A detailed description of each track's content is shown in Table 5. Good compatibility can be seen between the qualitative analysis presented in track four and the quantitative interpretation presented in tracks thirteen and fifteen. Perspective gas-saturated intervals correspond to sandstone and mudstone with low water saturation coefficient and high porosity. The last two tracks present high resolution results resampled to $0.05 \mathrm{~m}$ to enable the two models of different scales to be compared. It caused the calculated values to be averaged and made it possible to set the evaluated models together. 


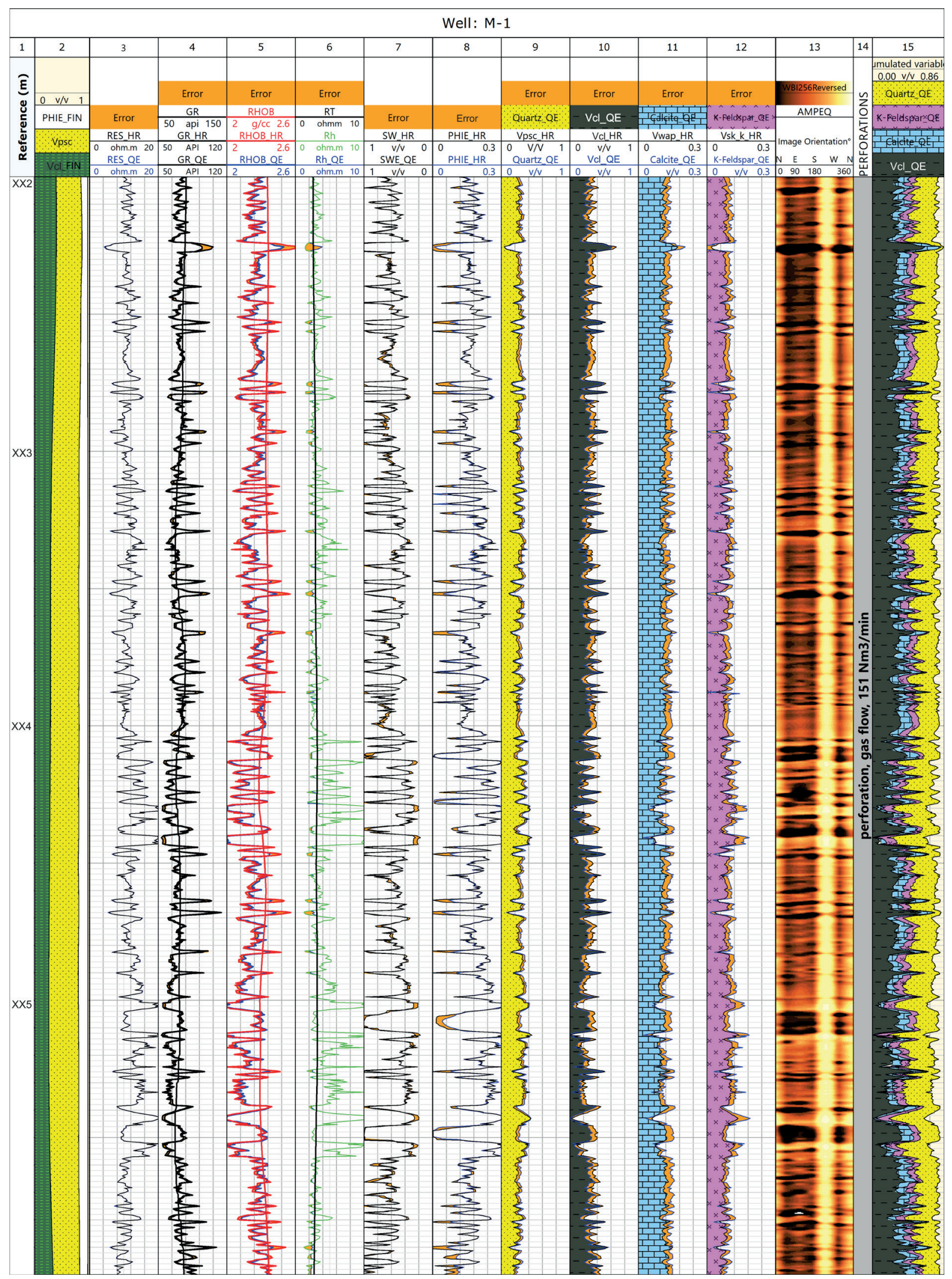

Fig. 6. Conventional well log interpretation in the second track versus high-resolution processed well logs, clay volume, porosity, water saturation, and the volumes of minerals 


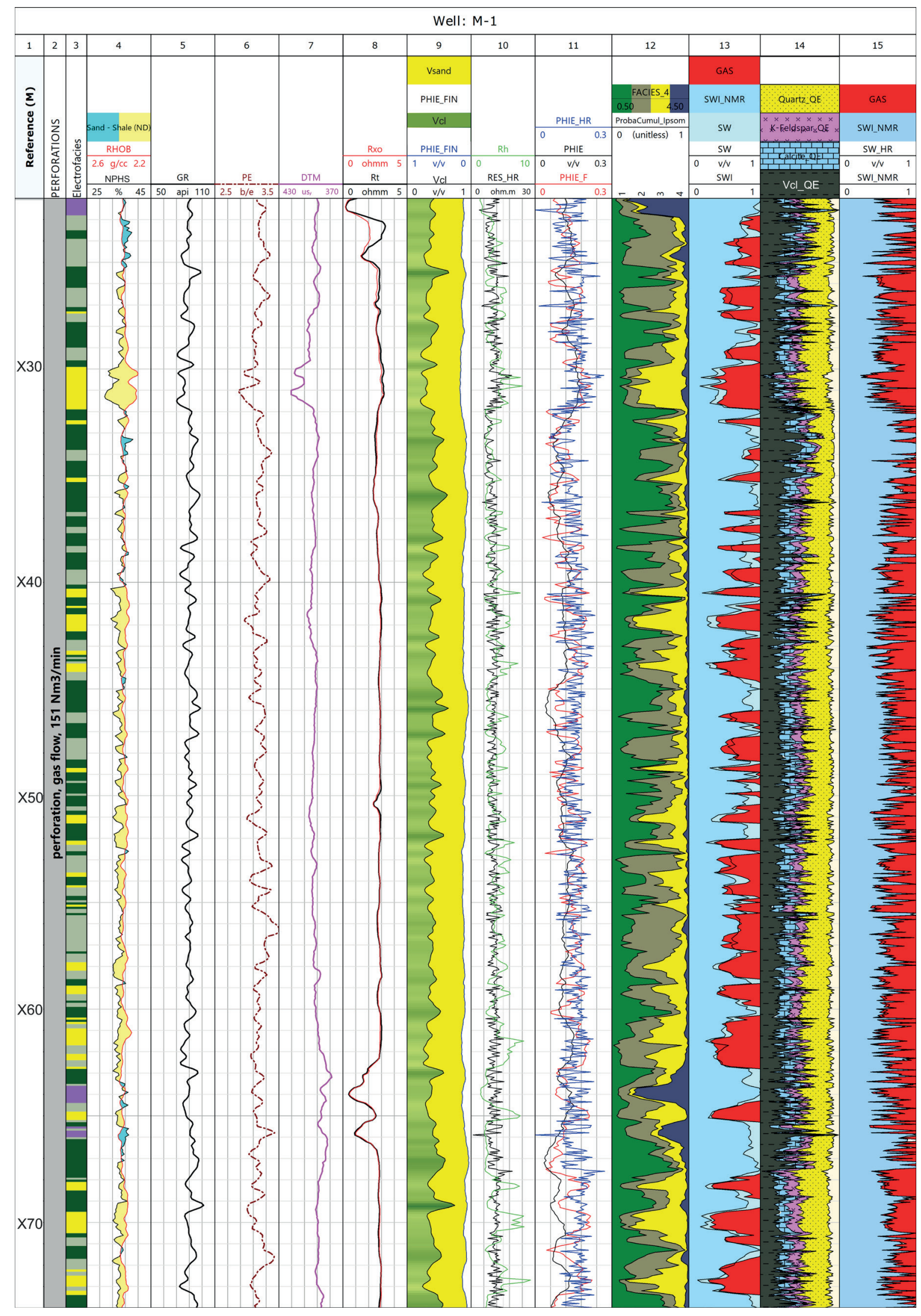

Fig. 7. The results of interpretation obtained from two methods 
Table 5

Description of the content of each track presented in Figure 7

\begin{tabular}{|c|l|}
\hline Track & \multicolumn{1}{|c|}{ Description of track content } \\
\hline 1 & Measured depth \\
\hline 2 & Perforations and its results \\
\hline 3 & $\begin{array}{l}\text { Electrofacies; yellow - fine-grained sandstone, grey - mudstone, green - claystone, violet - mudstones with } \\
\text { iron compounds }\end{array}$ \\
\hline 4 & Neutron porosity (NPHS) and bulk density (RHOB) for qualitative interpretation \\
\hline 5 & GR - gamma ray \\
\hline 6 & PE - photoelectric factor \\
\hline 7 & DTM - compressional slowness \\
\hline 8 & Rt - formation resistivity and Rx0 - resistivity of the flushed zone, measured with the HRAI \\
\hline 9 & $\begin{array}{l}\text { Lithological model evaluated using conventional interpretation methods: clay volume, matrix (Vsand), } \\
\text { effective porosity (PHIE_FIN) }\end{array}$ \\
\hline 10 & $\begin{array}{l}\text { RES_HR - microresistivity from the XRMI borehole imager and Rh - horizontal resistivity calculated based } \\
\text { on electrofacies }\end{array}$ \\
\hline 11 & $\begin{array}{l}\text { PHIE_F - electrofacies-based effective porosity, PHIE_HR - high-resolution (filtered) effective porosity, } \\
\text { PHIE_FIN - effective porosity obtained from neutron-density cross-plot }\end{array}$ \\
\hline 12 & $\begin{array}{l}\text { Probability curves of the occurrence of facies at each depth, yellow - fine-grained sandstone, } \\
\text { grey - mudstone, green - claystone, violet - mudstone with iron compounds }\end{array}$ \\
\hline 13 & $\begin{array}{l}\text { Water saturation coefficient based on electrofacies model. The SW was calculated using the Archie formula } \\
\text { with the use of PHIE_F and Rh as inputs. SWI irreducible water saturation was estimated from the } \\
\text { correlation between NMR measurements and the effective porosity (PHIE_F) }\end{array}$ \\
\hline 14 & $\begin{array}{l}\text { Lithological model evaluated using QE module and high-resolution XRMI data (sampling rate 0.05 m) } \\
\text { coefficient, SWI_HR - irreducible water saturation (sampling rate 0.05 m) }\end{array}$ \\
\hline 15 & $\begin{array}{l}\text { Model of the pore space saturation evaluated from high-resolution data. SW_HR - water saturation } \\
\text { (n) }\end{array}$ \\
\hline
\end{tabular}

\section{DISCUSSION}

The evaluated reservoir is a great example of how the properties of rocks depend on the scale of its interpretation. Although the qualitative interpretation of heterolith reservoirs enables to identify the most perspective intervals, the quantitative interpretation is a challenge, especially when the beds are very thin and the correlation between high resolution microresistivity measurements and conventional logs is poor. The paper presents two different approaches to evaluating thin bed gas horizons. The first, a very detailed one, is based on high resolution microresitivity data and the results of the laboratory measurements. The second one uses an artificial neural network to differentiate the reservoir in terms of its filtration and accumulation properties with the use of conventional well logs as inputs. Both methods have advantages and limitations, and both should be performed simultaneously with the qualitative analysis that are essential to specify gas saturated intervals. This is especially important when formation resistivity is evaluated, as it requires different assumptions of resistivity in water saturated and gas saturated intervals. The evaluated models of the petrophysical properties of heterolith reservoir allowed to re-define pay zone intervals and calculated Net/Gross values. Table 6 presents the average values of porosity and water saturation in the defined pay zones. The cutoffs were assigned as follows: PHIE $>0.04$ and SW $<0.65$. The conventional interpretation was performed with the used of the Indonesia equation, however it was observed that the use of this equation lowered the water saturation in intervals with a high clay volume that should be water saturated, while within the potentailly gas saturated intervals still remain highly water saturated. Generally, no approach using conventional measured resistivity as an input will be appropriate since every water saturation model needs proper formation resistivity to calculate reasonable results. Both presented methods show how formation resistivity in thin bedded reservoirs can be obtained. 
Table 6

Pay zones defined from the two evaluated models

\begin{tabular}{|l|c|c|c|c|c|c|}
\hline \multicolumn{1}{|c|}{ Flag name } & Gross & Net & Not Net & Net to Gross & Average PHIE & Average SW \\
\hline \multicolumn{7}{|c|}{ High-resolution interpretation } \\
\hline PAY & 104.5 & 41.308 & 63.19 & 0.395 & 0.18 & 0.53 \\
\hline \multicolumn{7}{|c|}{ IPSOM based interpretation } \\
\hline PAY
\end{tabular}

\section{CONCLUSION}

The first method showed a detailed interpretation of the reservoir but is based on one high resolution variable and laboratory measurements that allowed the evaluation of the high-resolution earth model. Meanwhile, the second approach uses information from all conventional well logs but the model has a lower resolution. The comparison of results obtained from the two presented methods is difficult because of the scale issue. The data were collected by two different tools with different levels of sensitivity and resolution. The conventional logging tool is not able to resolve very thin laminas and opposite high resolution microresistivity data are very sensitive and able to detect more details and lithology changes within the formation. The comparison of the two methods shows better compatibility within the thicker layers and worse when the beds are very thin. In the case of archival wells where no high-resolution logging is available, the use of neural networks enabled to evaluate accumulation parameters and define effective reservoir thickness. It allowed us to define pay zones and subdivided gas horizons into zones of different petrophysical and accumulation properties. Electrofacies based forward modeling of effective porosity and water saturation must precede the calculation of formation resistivity. The SOM Kohonen neural networks were also tested in other Miocene archival wells, within thick heterolith gas horizons where only four well logs (GR, PS, NPHI, RT) were available. The results were also satisfying, and the method was helpful with effective thickness definition and Net/Gross calculation. The obtained results were consistent with the results of perforations carried out at the evaluated intervals.

Due to the challenges in thin-bed reservoirs interpretation, it is worth considering the use of new well logging techniques such as MCI that simultaneously measure both vertical and horizontal resistivity. The tool measures formation resistivity in three dimensions and provides a more accurate evaluation of water saturation in anisotropic laminated and low-resistivity reservoirs. Also, High-Frequency Dielectric Tool (LOGIQ) is a device dedicated to the evaluation of thin bed reservoirs.

The author would like to thank the Polish Oil and Gas Company (PGNiG S.A.) for providing the data for this research and also the Schlumberger company for providing the Techlog petrophysical software that enabled the evaluation of the reservoir to be performed.

This research was funded by the Ministry of Science and Higher Education; order no. 0020/SG/20, archive no. DK-4100-8/20.

The authors have no conflict of interest to declare.

\section{REFERENCES}

Allen D.F., 1984. Laminated Sand Analysis. [in:] SPWLA 25th Annual Logging Symposium New Orleans, Louisiana, USA, June 10-13, 1984, SPWLA-1984-XX.

Bała M., 2011. Evaluation of electric parameters of anisotropic sandy-shaly Miocene formations on the basis of resistivity logs. Acta Geophysica, 59, 5, 954-966. https:// doi.org/10.2478/s11600-011-0033-1.

Borys Z., 1996. Aktualne problemy poszukiwań węglowodorów we wschodniej części przedgórza Karpat. Przegląd Geologiczny, 44, 10, 1019-1023. 
Boyd A., Darling H., Tabanou J., Davis B., Lyon B., Flaum Ch., Klein J., Sneider R.M., Sibbit A. \& Singer J., 1995. The lowdown on low-resistivity pay. Schlumberger Oilfield Review, 7, 3, 4-18.

Chapman S., Colson J., Everett B., Flaum Ch., Herron M., Hertzog R., La Vigne J., Pirie G., Quirein J., Schweitzer J., Scott H. \& Wendlandt R., 1987. The Emergence of Geochemical Well Logging. Technical Review, 35, 2, 27-35.

Jarzyna J., Bała M. \& Cichy A., 2009. Elastic Parameters of Rocks from Well Logging in Near Surface Sediments. Acta Geophysica, 58, 1, 34-48. https://doi.org/10.2478/ s11600-009-0036-3.

Klein J.D., 1993. Induction log anisotropy corrections. The Log Analyst, 34, 2, 18-27.

Kohonen T., 2001. Self-Organizing Maps. Springer Series in Information Sciences, 30, Springer, Berlin 2001. https:// doi.org/10.1007/978-3-642-56927-2.

Krzywiec P., Wysocka A., Oszczypko N., Mastalerz K., Papiernik B., Wróbel G., Oszczypko-Clowes M., Aleksandrowski P., Madej K. \& Kijewska S., 2008. Ewolucja utworów mioceńskich zapadliska przedkarpackiego w rejonie Rzeszowa (obszar zdjęcia sejsmicznego 3D Sokołów-Smolarzyny). Przeglad Geologiczny, 56, 3, 232-244.

Mollison R.A., Fannini O.N., Kriegshauser B.F., Yu L., Ugueto G. \& van Popta J., 2001. Impact of multicomponent induction technology on a deep water turbidite sand hydrocarbon saturation evaluation. [in:] SPWLA 42nd Annual Logging Symposium, Houston, Texas, June 2001, SPWLA-2001-T.

Myśliwiec M., 2004. Exploration for gas accumulations in the Miocene deposits of the Carpathian Foredeep using direct hydrocarbon indicators - verification of anomalies (southern Poland). Przeglad Geologiczny, 52, 4, 307-314.
Nooh A.Z. \& Moustafa E.A.A., 2017. Comparison of Quantitative Analysis of Image Logs for Clay Volume and Net to Gross Calculation of a Thinly Laminated Reservoir between VNG-NERGE and LAGIA-EGYPT. Egyptian Journal of Petroleum, 26, 3, 619-625. https://doi. org/10.1016/j.ejpe.2016.09.001.

Ramamoorthy R., Flaum C. \& Coll C., 1995. Geologically Consistent Resolution Enhancement of Standard Petrophysical Analysis Using Image Log Data. [in:] 70th SPE Annual Technical Conference and Exhibition, Dallas, Texas, USA, October 22-25, SPE 30607.

Ruhovets N., Rau R., Samuel M., Smith H. Jr. \& Smith M., 1992. Evaluating thinly laminated reservoirs using logs with different vertical resolution. [in:] Hurst A., Griffiths C.M., Lovell M.A., Morton A.C., Worthington P.F. (eds.), Geological Applications of Wireline Logs II, Geological Society Special Publications, 65, Geological Society of London, 99-121. https://doi.org/10.1144/GSL. SP.1992.065.01.08.

Serra O., 1984. Fundamentals of Well-Log Interpretation. Developments in Sedimentology, 15, Elsevier.

Serra O. \& Andreani M., 1991. Thin Beds: A Guide to Interpretation of Thinly Layered Reservoirs. Schlumberger.

Shahinpour A., 2013. Borehole image log analysis for sedimentary environment and clay volume interpretation. Norwegian University of Science and Technology, Department of Petroleum Engineering and Applied Geophysics. https://core.ac.uk/download/pdf/52100408.pdf [access: 1.02.2021].

Zawisza L. \& Nowak J., 2012. Metodyka określania parametrów filtracyjnych skał na podstawie kompleksowej analizy danych geofizyki otworowej. Wydawnictwa AGH, Kraków. 